\title{
Causal Loop Diagram (CLD) As an Instrument for Strategic Planning Process: American University of Nigeria, Yola
}

\author{
Apollos bitrus Goyol ${ }^{1} \&$ Bolchit Gideon Dala ${ }^{2}$ \\ ${ }^{1}$ College of Business and Administration, American University in the Emirates, United Arab Emirate \\ ${ }^{2}$ Department of Special Education and Rehabilitation Sciences, Faculty of Education, University of Jos, Nigeria \\ Correspondence: Apollos bitrus Goyol, College of Business and Administration, American University in the \\ Emirates, United Arab Emirate. E-mail: apollos.goyol@aue.ae
}

Received: September 18, 2013

Accepted: November 7, 2013

Online Published: December 18, 2013

doi:10.5539/ijbm.v9n1p77

URL: http://dx.doi.org/10.5539/ijbm.v9n1p77

\begin{abstract}
American University of Nigeria (AUN), was established in 2005 and has emerged as Nigeria's most preferred university. Located in Yola, Adamawa State, North-eastern Nigeria, the university was conceived in response to the need for a world-class university in sub-Saharan Africa. The university offers an American-style education modeled after the curriculum of American universities with corresponding approaches to teaching and assessing students. Nigeria with a population of over 160 million. It is estimated that 3 million students graduate from high schools every year. With 124 universities with less than 1million enrollment spaces. The implication is that there is a serious shortfall in the number of students that wants to further their education. With this prevailing situation every university must do everything possible to provide prospective students with placement.

Therefore, the main objective of this study is to take a critical look at the possible ways that the university can strategically adopt to attract this huge number of high school graduates using the Casual Loop Diagram (CLD) for identifying, managing and utilizing Critical Performance Indicators (CPIs) in tackling existing problems through coordinated partnership and collaboration towards appropriate policy recommendations. The most useful tool for identifying the causes of problems is a cause-and-effect diagram, also known as a Fishbone or Ishikawa diagram which is very similar to the CLD. The results of the survey that was administered to a convenient random sample of AUN students $(\mathrm{N}=369)$. The results indicated that a large percentage believes that the university has a very good prospect of achieving its set goals as a development university if the standards and institutional characteristics can be sustained and improved upon. To better understand the KPI in relation to the results, the Casual Loop Diagram (CLD) was used to analysis the relationships between the results the KPI. This would assist in better approach in the recruitment process.

Given that this is a pilot study, the results are only preliminary and merely indicate how to improve policy and program decisions especially for AUN as a development university. The short time outcome and impact of the study has provided some insight into the college choice process of choosing a college using the CLD. Also it is important for admission professionals understand the factors that shape the college decision-making process and the stages students move through as they make decisions.

The flexibility of the design allows for adaptation to any institution's unique structure and mission.
\end{abstract}

Keywords: college, choice, causal look diagram, key performance indicators, American university in Nigeria

\section{Introduction}

\subsection{Background and Significance}

American University of Nigeria (AUN) founded in 2005 in response to the need for a world class university in sub-Saharan Africa. It currently runs 12 undergraduate programs in 3 schools: School of Arts and Sciences; School of Business and Entrepreneurship; and School of Information Technology \& Communication. The goal of AUN is to train the future leaders of Africa and to serve as both a stimulus and an agent of economic development throughout the region. The university is located in the city of the Yola capital of Adamawa, one of Nigeria's 36 states. The campus is attractive, modern and has 24/7 power supply. It has a student population of over 1,258 which occupies 500 hectares of land. All buildings are fully air-conditioned with modern facilities. The entire campus has wireless internet and dorms are provided with cable television in common rooms 
The AUN seeks to become a great center of learning and research in Nigeria and Africa, and a catalyst for development in the entire world. In the words of its Founder, it sees its role as a, "Development University". It will thus be a university honoring the traditional roles of repository and transmitter of culture and knowledge, and become a center of new knowledge. But it will also see as its focus the practical role that a great university must play in the development of a great nation.

This study seeks to examine the college choice process using students studying at the AUN, Yola Adamawa State using the Casual Loop Diagram (CLD). This work will identify, manage and utilize Key Performance Indicators (KPIs) in tackling existing problems through appropriate policy recommendations. A total of seventeen (17) KPI frameworks has been identified. The students are full-time students who immediately attended a four-year university upon graduation from secondary/high school.

The Competitive Positioning \& Enrollment Committee (CPE) are one of the 3 arms of AUN's Strategic Planning Council. It has responsibility for identifying the University's competitive advantages, with a view to marshalling plans, for a systematically organized and sustainable enrollment of outstanding students into AUN, from a diversity of backgrounds and regions. The process seeks to lay emphasis on competitive programs, facilities, faculty, students, administrators and recruitment strategies. In achieving this goal, the committee brainstormed through four weeks of action and activity, culminating in the following draft process for an ongoing CPE blueprint to the Strategic Planning Council.

- Identified 9 key questions used in SWOT analysis.

- Conducted an on-campus student survey to secure reasons why students choose AUN, and leave the University before graduating.

- Develop a survey questionnaire that was administered to 369 students, which also integrated the 9 key questions, after which the result of the survey was analyzed to produce an interim report.

- The Office of Admissions produced a summary of applicants' responses and preferences during recruitment activities, which provided a valuable resource that, aided the Committee's work.

- The group brainstormed, though exhaustively, to produce an additional perspective from the experiences of members outside of the AUN students' survey report and the admissions information.

- A total of seventeen 17 KPI frameworks has been identified. Through the CLD diagram, the KPI's present an organic chain of understanding the enrollment problems and how they impact each other.

This study is not fully conclusive but provides a foundational framework for the ongoing strategic planning process at the AUN as far as competitive positioning and enrollment is concerned.

The following major areas of concern were considered as important to the study as provided for by the admissions office as mentioned earlier:

\subsection{Admissions Application Report}

\subsubsection{Why AUN?}

American University of Nigeria is the choice University in Nigeria. Answers

$\checkmark$ A liberal arts education; in an American style University.

$\checkmark \quad$ Students can have a minor besides their major.

$\checkmark$ Students can graduate with two degrees.

$\checkmark \quad$ Students can change their majors at any point without losing money or time.

$\checkmark \quad$ Work-study program.

$\checkmark \quad$ Wireless campus.

$\checkmark \quad$ 24/7 electricity, running water and air-conditioned classes and closed areas.

$\checkmark$ Luxurious dorms.

$\checkmark \quad$ Study Abroad Program.

\subsubsection{The Most Important Considerations for Applying to AUN}

$\checkmark \quad$ The geographical locations of the cities from which we are recruiting. For example we are entitled to get more students from Abuja, and other surrounding cities, than we get from Lagos, Port Harcourt and Warri. 
$\checkmark$ Admissions requirements, i.e. high school leaving examination results, JAMB results, SS1, SS2 and SS3 transcripts, etc.

$\checkmark \quad$ Financial considerations, i.e. the financial status of parents and whether or not we are offering academic scholarships, need based scholarships, sports scholarships, financial aid, etc.

$\checkmark \quad$ Meeting the requirements and deadlines on time due.

1.2.3 Short and Long Term Plan to Attract and Retain Enough Numbers of the Most Outstanding Students

$\checkmark \quad$ Maintain and extend services, i.e. classrooms, air-conditioning, dorms, library, transportation, power, internet, nutrition, sports, etc.

Maintain a proper and reasonable annual tuition and fees increase. The more reasonable the tuition and fees are the more students will enroll and the higher the income for the University.

$\checkmark$ Look into the best interest of students, and not the profit to be made.

$\checkmark$ Adding more majors, especially in the fields of engineering, core sciences, social sciences, agriculture, education and architecture. We are losing many students due to the limited number of majors we have.

$\checkmark \quad$ Introduce more aggressive activities rather than just sports and chess. Students should have more interesting things to do, other than sports and board games. We suggest a Theatre group, musical groups, talent show, folk dancing, quire, scientific inventions, etc.

$\checkmark \quad$ Identify the very best high schools and create lasting and sustainable partnerships with such schools. It is imperative to partner the schools that produce these students. This can be effectively achieved through a variety of recruitment methods namely: use of alumni, students and faculty.

AUN's recruitment process in the short run has to be target specific. This involves identifying and attracting the very best students.

$\checkmark \quad$ To achieve this AUN would have to identify the following; who is a good prospective student? Which schools produce the best students? Where are the schools that produce the best students located? How does AUN attract these students? When these questions are answered, it would then be necessary to strategically establish proper partnerships with these high schools.

$\checkmark$ AUN would have to lure top high schools with attractive incentives e.g. donations (equipment, gifts, trinkets), AUN sponsored seminars, lectures, competitions etc.

Another key short-term plan for AUN in attracting and retaining the very best students is personal empowerment. The admissions office needs to be continually driven by creativity and innovation in strategy and approach to students' recruitment for which they have always been on top.

\subsubsection{Long Term Goals}

$\checkmark$ Due to the uniqueness of the American style of education to Nigeria, which AUN is offering, it is imperative for the university to target for job recruitment purposes (admissions office) individuals who have a good understanding of this system.

$\checkmark \quad$ In the long run AUN should specifically target hiring of its graduates into permanent positions in the admissions office.

$\checkmark$ Also the use of the alumni association through its alumni recruitment volunteer program would be highly effective.

$\checkmark$ AUN's long-term goals in students' recruitment should also include expanding beyond the shores of Nigeria and into other African countries for the best students. There exists a huge market of prospective students seeking quality education in a secure, serene and peaceful environment (American style) in many African countries. AUN can begin by targeting not just neighboring Western African nations, but also rich African countries that lack good tertiary educational system e.g. Congo DR, Gabon, Angola, Sudan, Ethiopia, etc.

\subsubsection{Retentions}

While there are many possible (inexhaustible) reasons why students would leave AUN from other universities, the following reasons feature prominently in influencing this negative trend.

$\checkmark \quad$ Lack of desired major of study;

$\checkmark \quad$ Lack of necessary facilities (recreational, infrastructural);

$\checkmark \quad$ Poor academic performance; 
$\checkmark \quad$ Tuition and fees increase;

$\checkmark \quad$ Failure to adjust to American education/curriculum.

\subsubsection{Cost}

Obtaining a degree might be very expensive, but it is an investment worth making. Often times schools are ruled out based on cost, even though the school might be a perfect option that fits our interest. Below are samples of tuition fees which came from the Washington Higher Education Coordinating Board (WHECB) report of its $39^{\text {th }}$ survey of tuition and fee rates at some selected schools in the United States. The projections for financial year 2009 through financial year 2011 were based on an annual conservative 5.3\% increase in Tuition and Fees in some schools across the globe.

Table 1. Estimated average tuition fees at selected international universities

\begin{tabular}{cc}
\hline Institutions & Tuition fees \\
\hline University of Nairobi, Kenya & $\$ 3,000$ \\
American University of Dubai & $\$ 19,617$ \\
American University of the Caribbean & $\$ 35,400$ \\
\hline
\end{tabular}

Table 2. Estimated average tuition fees at a few selected Nigerian universities

\begin{tabular}{ccc}
\hline Institutions & In USD \$ & In Naira N \\
\hline Adamawa State University & 404.86 & 60,000 \\
Al-Hikman University & 2,699 & 400,000 \\
American University of Nigeria & $14,500.49$ & $2,149,000$ \\
\hline
\end{tabular}

\section{Information Gathered/Literature Review}

The review of literature plays a vital role in each study, and needless to say, in this study literature regarding the defined problems and the operational concepts related to the study has been collected and reviewed appropriately The first section of the chapter, are related reviews of previous studies that uses the Causal Loop Diagram (CLD) is a causal diagram that aids in visualizing how the different variables in a system are interrelated. To understand a complex system it is necessary to list the variables / components that re important to that system and how these variables are interrelated. This can be done by putting them in a graph, where each variable is represented by a point, and each interrelates with an arrow. To create a Causal Loop Diagram: system follows these basic rules as described by Duke Rohe.

Step 1. Start with a problem - characterize it in simple terms such that it would be clear to all who have an even peripheral understanding of it. What is wrong? What is it you don't like? What is the root source of the problem?

Step 2. Begin defining the causes of the problem. Start with a fact in the loop. State it in sentences such that there is a relationship between cause and effect.

Step 3. Each cause becomes an effect of the next. To find a cause, ask, Why. To find out the effect, ask, what happens. It's a probing process of why's.

Step 4. Show relation between Cause to Effect as reinforcing (+) or (-). This does not indicate good or bad it just means as the cause goes intensifies, effects does too $(+)$ and as cause diminishes, the effect does also (-).

Step 5. Seek out systems and subsystems (series of loops that feed into each other) of loops

Step 6. Distinguish between perceived and real facts. Graph over time to better characterize them.

Step 7. To begin reducing an effect of a cause, take a loop out and ask: if this effect were fixed or did not matter what could be done to lessen its impact on the loop. This entertains possible solutions.

And the process starts by:

- Identify your variables by getting a list of all relevant quantifiable factors. (be careful and keep it simple by keeping the list short). Remember the art of modeling is the ability to have the correct level of complexity. 
- Determine which factor causes change in which other factor, and use arrows to indicate these relationships. Note-Not all systems have loops. Do not force your factors into a specific design.

- For each relationship decide whether the correlation is positive or negative (it should never be both.

- Identify all loops or negative (or stable) causal feedback loops. (Much like mathematics, two negatives make a positive, a loop with an even number of "_"s is always a positive feedback loop, while the rest are negative.

T. Micheal Toole (2005), recognized that many large projects do not meet their time and cost goals. Moreover, as projects get more complex, as completion time becomes more critical, and as concurrent design and implementation (such as fast track construction) becomes more prevalent, failure to meet project goals is likely to become increasingly common. Project manager researchers he said have written that one reason project goals are often not met is that the project management concepts and tools used today are too linear and deterministic. These researchers suggest that system dynamics concepts and tools, such as causal loop diagram and detailed models, should be integrated into project management practices to all project managers to better understand the structure of the system in which project management occurs and consequently better plan and control projects. He concluded CLD allows project managers to better predict potential consequences of their decisions and actions resulting from feedback loops within the project management system. My paper agrees with his reasoning, which means once the problem is identified, the cause and effects that can easily understand this will help guide the management of AUN with their strategic plans as the school expands.

Kiani, Gholamian, Hamzehei, and Hosseini (2009) found that we live in a competitive, rapidly changing and an increasingly uncertain economic environment that makes business decisions complex and difficult. Companies are confronted with new information and communication technologies, shorter product life cycles, global markets and tougher completion. In this hostile business environment firms should be able to manage multiple distribution channels, complicate supply chains, expensive IT implementations and strategic partnerships and still stay flexible enough to reach to market changes. Astonishingly, the concepts and software tools that help managers facilitate strategic business decisions in this difficult environment are still scarce. Using the concept of business models can help companies understand, communicate, share, change, measure, simulate and learn more about the different aspects of e-Business in their firms. Better understanding of e-Business models helps managers and related staff to better apply the business models. The main objective of their paper is to use CLD as a useful tool to capture the structure of e-Business systems in order to achieve a better understanding of an e-Business model. The proposed CLD provides managers with significant insight into the e-Business models. This proposition also supports why the use of CLD for AUN is needed especially with the competition they are facing with the establishment of more 30 new universities (both private and public) in Nigeria in the last 5 years.

In this Intervening and Changing: Looking for Meaning in Interactins, Vermaak (2007) said Causal Loop diagrams can help in tackling complex issues effectively. Until the 1970s this type of diagram was the main technique to be described. It has since become clear that for the diagrams to be effective, it is better for people to participate in creating and applying them. Working interactively with causal loop diagrams has increasingly gained attention. You don't learn as much from reading a causal loop diagram as you do from making one. Applying acquired insights or accelerating decision-making also requires working interactively with diagrams. This means that change agents should not only be able to make diagrams, they should also be able to design and facilitate the participation of the parties concerned. The aim is to further the practical use of causal loop diagrams so that this becomes a craft in organizations rather than just a popular idea. That is exactly what the President of AUN wanted the strategic implementation committee to come up with and that was why CLD was adopted as an instrument for strategic planning.

The second section of this chapter defines and describes the concepts and importance of college education as obtained in Nigeria.

When do young people begin to think of going to college? Why do they think about college? Who and what motivate them to attend college? Are there factors that influence their choice of college? This research was backed up by a survey conducted in the spring semester of 2011 at the American University of Nigeria (AUN), with a convenient random population of participant from all levels of the university.

A large majority of Nigerians (families and education stakeholders) believes everyone in a modern society should obtain some form of postsecondary education and training. Such a faith in higher education comes from the realization that the world is growing fast; development in science, technology, humanity and the arts have revolutionized the world we live in today. The concepts and tools we use to measure the occurrence of events in our society have evolved from the Stone Age to the Jet Age. The effects are visible even to the benefit of 
mankind. There is no denial of the fact that as the world evolves, the thoughts and abilities of man have to change in order to handle events in the society. Acquiring formal education and training is surely the way out. The quest for knowledge especially at a higher level has continued to be seen as the surest path to personal fulfillment, economic success (income potentials) not to mention its lasting impact on the lives of individuals who take to it. Studies have shown that increased levels of postsecondary education have led to higher salaries, longer working lives, more career mobility, and an increased quality of life (Bowen 1977; Leslie and Brinkman 1988; Pascarella \& Terenzini, 2005).

Economists usually deliberate on the nature and extent of the economic benefits of higher education to society and individuals, and the majority still believe that individuals and countries at large benefit from more educated citizens (McGregor, 1994; Wellman \& Ewell, 2007). Economic competitiveness, enhanced government revenues, enhanced social equality, higher level of productivity and the empowerment of citizenry to achieve the country's goals are the major benefits accrued from top level education. The educated workforce has been seen over the last decades as an essential component to economic competitiveness in the society.

For these reasons policy makers have enacted laws that favor the establishment of private schools which have added to the number of public schools in the country. Invariably, this has resulted in a continuous annual increase in the number of students enrolled in schools in the past two decades. In addition, there are a large proportion of students graduating from secondary schools to post-secondary. This has also been used as a criterion to evaluate the quality of education in many communities.

\section{Methodology}

\subsection{Methodology}

\subsubsection{Subjects}

Subjects for this study are students enrolled full-time at the American University of Nigeria, Yola.

\subsubsection{Instruments}

The purpose of this project was to pilot a study examining the university choice process of students currently attending the American University of Nigeria. As preliminary research, the study is limited but will hopefully be used to assist schools, parents and other stakeholders with counseling students as they decide which university to attend.

A questionnaire made up of 20 questions, was administered to all subjects. The emphasis was on school fees, admissions, students' learning and satisfactions gained from facilities and other services rendered. The report on the pilot survey "Making AUN Your First Choice" presents findings based on descriptive representations to help gain valuable knowledge regarding AUN's strategic plan. The aim is to ensure that every student is offered a consistently high standard of service, facilities, and qualitative lifelong learning knowledge, and skills. Being a pilot study, the validity and reliability of the instrument have not been established.

The CLD was used to establish any cause and effect and correlations' relationships between, the KPIs.

\section{Analysis of Results}

The data from the completed questionnaire were complied into descriptive representations that will be useful for future studies and provide preliminary insight about the reasons why the choice AUN for their undergraduate studies.

The findings from questioning had a total of three hundred and sixty nine (369) participants indicate some of the main strength and weaknesses of AUN. Below is an outlined summary of the survey analysis:

Eighty three percent $(83 \%)$ of the sample population believes AUN's school fee is high compared to other higher institutions and suggested that the fee should be reduced. While the remaining $17 \%$ hold that the fee is reasonable.

However, in a separate scenario, $69 \%$ of the students who responded to whether the fee is justified going by the quality of facilities and faculty available at AUN, do not believe the fees are justified, while $31 \%$ think the fees are justified.

When asked why they chose AUN, some of the responses include:

$\checkmark \quad$ I did not choose AUN.

$\checkmark \quad$ My parents did (majority).

$\checkmark$ AUN was the last option when every other alternative failed (majority). 
$\checkmark$ Having the experience of an American Style University in Nigeria.

$\checkmark \quad$ The publicity made about the school.

$\checkmark \quad$ My parents wanted me to stay close to them.

$\checkmark \quad$ The school was close to home.

$\checkmark \quad$ Wanted a school where I will not be delayed or distracted by strike.

$\checkmark$ Had no visa to study abroad.

$\checkmark \quad$ It is the best school in Nigeria and the only school that offers my Major.

These were some of the reasons that revolved amongst a majority of the sample population (the student).

\title{
4.1 Place of AUN among Other Institutions
}

When asked where the students place AUN on a scale of $1-5$ with 5 being the highest; $5 \%$ of the counts were for $1,12 \%$ for $2,37 \%$ for $3,31 \%$ for 4 and $15 \%$ counts were placed in 5 . The average rating was approximately 3.35 out of 5 .

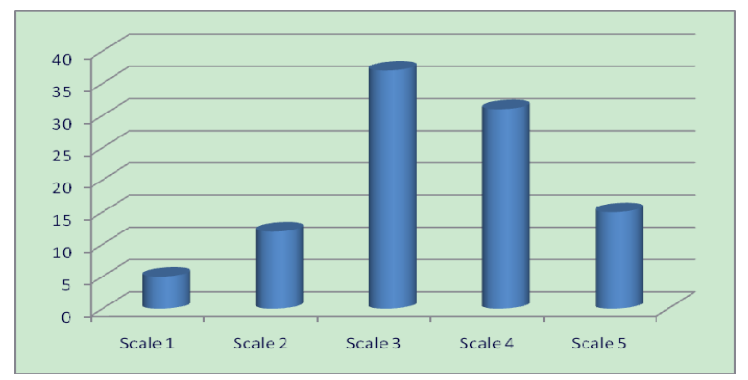

Figure 1. A chart showing how students rate AUN on a scale of 1 to 5 , with 5 being the highest

\begin{abstract}
$\checkmark \quad$ The majority of respondents believe that students abandon AUN after gaining admission because they were misinformed, and also had less information about the school. Other reasons which were also given by the students are: high school fees, poor level of facilities in the school, drug issues (parents are being informed about drug "trafficking" in AUN) and also the hard study condition in Yola.

$\checkmark \quad$ Some of the reasons given by students as to what will make them leave the school include: continuous increase in school fees, lack of enough faculty in the schools, a drop in the school's reputation (because many people now assume AUN is made up of druggies and spoilt brats), gain admission to study overseas, falling academic standards, if there is a fall in the level of services rendered in the school, etc.

On the contrary, the majority of respondents suggests that the following reasons will make them stay in AUN: constant supply of electricity, water and internet services, presence of high profile teachers, good students' social life on campus, better programs and facilities, improved academic standard, stable or low tuition, more interesting and working environment, job prospect after graduation etc.
\end{abstract}

\subsection{How to Secure Student Retention at AUN}

The majority of the respondents strongly suggests that for AUN to attract the best of students, the following need to be done;

- Have a reasonable JAMB cut off point for admission, and an AUN entrance examination should be introduced to ensure that only the best of students enrolled in the University.

- The school fees should be reasonable at least worth the services rendered.

- Scholarship should be granted not just students who are academically good but also those who are outstanding in sporting activities.

- Improve facilities by building more hostels, gyms, recreational centers on campus, etc.

- Ensure adequate publicity for all the programs and activities of the University. 


\subsection{Need for More Students Services}

Other student services suggested include the following:

$\checkmark \quad$ Therapy Session for depressed people;

$\checkmark \quad$ Excursion trips fully paid by the University;

$\checkmark$ Recreational centers;

$\checkmark \quad$ More hands on practical experience;

$\checkmark$ Transportation to Jimeta on weekends;

$\checkmark \quad$ Alternate cafeteria;

$\checkmark \quad$ Introduce inter dorm activities;

$\checkmark$ Better football pitches;

$\checkmark \quad$ Early completion of the library building;

$\checkmark$ Relaxation spot, swimming pools, talent hunt and dance competitions;

$\checkmark$ More hostels etc.

\subsection{Pre-College Program at AUN?}

When asked if they would have joined a pre-collegiate program if offered at AUN, 56\% responded NO, while the remaining $44 \%$ said YES, although any attached conditions to their answers. Most of the conditional affirmations centered on reasonable school fees.

\subsection{Recruitment Suggestions for Students}

- Improve marketing strategies, adverts and other ways of creating awareness. To that effect respondents suggested that AUN should be objective when they create such awareness.

- Increase the number of open house sessions; get more students involved in recruitment activities.

- Make the school fees reasonable and provide more scholarship.

- Bring in new courses and makes the catalogue more stable.

- Continue with high school visitations to sell AUN.

- Use current students and alumni in collaboration with public relations.

Table 3. Some of the newly suggested majors and their percentages

\begin{tabular}{|c|c|c|c|}
\hline S/No & Majors & $\begin{array}{c}\text { Categories } \\
\end{array}$ & Percentages \\
\hline 1 & Medical Sciences & Pre-Medicine, Nursing, Medicine \& Surgery & $28 \%$ \\
\hline 2 & Law & Pre-law, Business Law, Civil, Cultural \& Social & $27 \%$ \\
\hline 3 & Engineering & $\begin{array}{l}\text { Mechanical, Electrical/Electronics, Telecommunication, } \\
\text { Robotics, Computer, Civil, Petroleum, PetroChemical, } \\
\text { Chemical, Oil \& Gas }\end{array}$ & $18 \%$ \\
\hline 4 & Arts & $\begin{array}{l}\text { Religious Studies, Criminology, Theatre Arts, Film } \\
\text { Studies, Mass communication, Journalism, Music, } \\
\text { Interior-Design,Sociology, etc. }\end{array}$ & $10 \%$ \\
\hline 5 & Environmental Sciences & Architecture, Building Technology, Land \& Survey & $9 \%$ \\
\hline 6 & Business & $\begin{array}{l}\text { Project Management, Human Resource Management } \\
\text { Hospital Management, Finance, International Business }\end{array}$ & $4 \%$ \\
\hline 7 & Natural Sciences & $\begin{array}{l}\text { Mathematics, Statistics, Computer, microbiology, Artificial } \\
\text { Intelligence, Geology,Geophysics, etc }\end{array}$ & $3 \%$ \\
\hline 8 & Pharmaceutical Sciences & Pharmacy & $2 \%$ \\
\hline
\end{tabular}




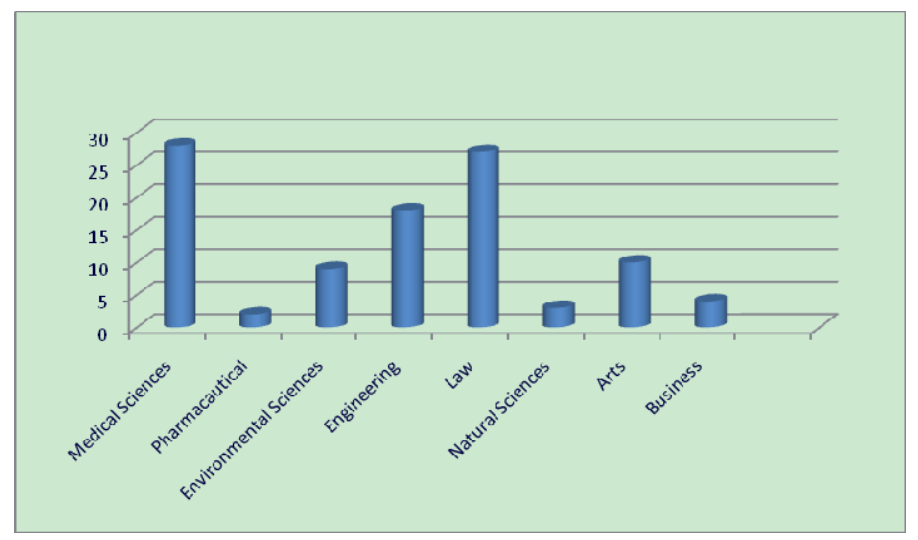

Figure 2. A chart showing suggested majors by the students

$\checkmark \quad$ When asked if students feel AUN has enough facilities for sports, $15 \%$ answered YES while the remaining $85 \%$ said NO.

$\checkmark$ On whether students were happy with cafeteria services only 15\% answered YES and 85\% said NO, the reasons were not far-fetched from the following:

- No local dishes always have carbohydrates e.g. rice as a meal. There should be more varieties.

- The meals lack taste and sometimes served spoilt or rotten.

- Cafeteria staffs have little respect for students. They should be courteous.

- Get the worth of what I pay, not that I pay N32, 000 for 30 tickets, when 1 ticket is worth N400, that's a rip-off.

- Provision should be made for competitions; WAC should not be the only one on campus.

- Need bigger meat and free drinks should be provided per meal etc.

$\checkmark \quad 67 \%$ of the Student attests to the fact that they are happy with their dorms, while $33 \%$ are not.

$\checkmark \quad$ Meanwhile $70 \%$ believe their dorms are clean and well maintained as opposed by $30 \%$.

$\checkmark$ On the other hand, 55\% turned down the fact that maintenance requests are efficient as opposed by $45 \%$ who believe the maintenance request are efficient.

$\checkmark 51 \%$ attests to the fact that everything in their rooms is in working order but $49 \%$ ticked NO.

$\checkmark$ On the issue of lightening being sufficient in their rooms, 80\% ticked YES while 20\% ticked NO.

$\checkmark$ As regards security, $82 \%$ of the respondents believe the school is safe.

\subsection{Casual-Loop Diagram (Cld) of Key Performance Indicators (Kpis)}

A good CLD provides good insight on a problem situation. Key Performance Indicators are quantifiable measurements, agreed to beforehand, that reflect the critical success factors of an organization. They will differ depending on the organization.

- A business may have as one of its Key Performance Indicators the percentage of its income that comes from return customers.

- A school may focus its Key Performance Indicators on graduation rates of its students.

- A Customer Service Department may have as one of its Key Performance Indicators, in line with overall company KPIs, percentage of customer calls answered in the first minute.

- A Key Performance Indicator for a social service organization might be the number of clients assisted during the year.

Whatever Key Performance Indicators are selected, they must reflect the organization's goals, they must be key to its success, and they must be quantifiable (measurable). Key Performance Indicators usually are long-term considerations. The definition of what they are and how they are measured do not change often. The goals for a particular Key Performance Indicator may change as the organization's goals change, or as it gets closer to achieving a goal. 
It is developed simply by tapping into, unifying and making explicit the mental models of teams and using this as the basis for Policy Recommendations on the problem situation. A CLD shows the key influences (system variables) believed to impact the problem situation and how they each impact others and are impacted upon (in the causal loops that bind them together).

\subsection{Identification \& Explanation of Key Influence Factors (Kind of CPIs-Critical Performance Indicators)}

- Target Recruitment Shortfall—gap between where we want to be in recruitment numbers per semester \& where we are actually, on average.

- Level of Interest, e.g. as shown by prospective students based on the number of inquiries prior to their enrollment at AUN.

- Transformation Rate, i.e. percentage of those expressing interest that are transformed into actual students.

- Uniqueness \& Quality of Programs, e.g. programs such as Software Engineering, Petroleum Chemistry, Telecommunications \& Wireless Technology, etc. that are unique to AUN attract a lot of students \& hence must be strengthened before they work in the opposite direction.

- The quality of AUN's programs and the diversity and world-class faculty pool should be reflected in the quality of delivery and awareness the University creates about the same.

- Diversity of Programs.

- The American Model.

- Student Retention Rate.

- Quality of Prospects, e.g. from JAMB scores \& other entry criteria.

- Coverage \& Student Compositions especially number of international students—-this can be an important component affecting the reputation \& interest in the University.

- Reputation, i.e. an indicator for the image or perception of AUN e.g. measured by recruitment figures \& level of interest shown.

- Recruitment Costs - should be measured as a relative cost from year to year \& against the first year costs - should have a target rate at which costs should be falling as AUN becomes more reputable

- Informativeness of Prospects e.g. based on tracking their criteria for choice of AUN.

- Freshman Preparedness for American University of Nigeria.

- Housing \& Facilities.

- Quality of Awareness Messages.

- Tuition \& Other Fees.

- Attractiveness of Location-largely a perception that can be built-Yola is seen as remote and lacking access to key opportunities but is also known to be a very peaceful $\&$ secure place to live and work.

\subsection{Causal Loop Diagram Model for CPE}

The CLD shows the key factors believed to influence the resulting outcome of a system for Competitive Positioning \& Enrollment (CPE) including the overriding performance parameter(s) being monitored. The latter can be for example the Target Recruitment Shortfall seen as the gap between where we want to be in recruitment numbers and what we are actually succeeding to get. Other key CPIs are Level of Interest \& Recruitment Cost. The key interconnections and interactions between these influences especially the feedback loops or chain of interconnections that tie a set of influence factors in a loop such that a change in a variable ripple through these interconnections to re-affect itself over time are key determinants of the resulting system behavior or outcome. As an example, the loop in red between Target Recruitment Shortfall \& Recruitment Cost, will contribute to the resultant range of responses or outcomes of the system. The loop shown is a balancing or equilibrium seeking, which means the 2 influences work together for some ultimate stabilizing output, in this situation trying to hit the target recruitment numbers. Using simple diagrams to show how variable/components of a system are influenced or related and how feedback is used through the system for improvement. 


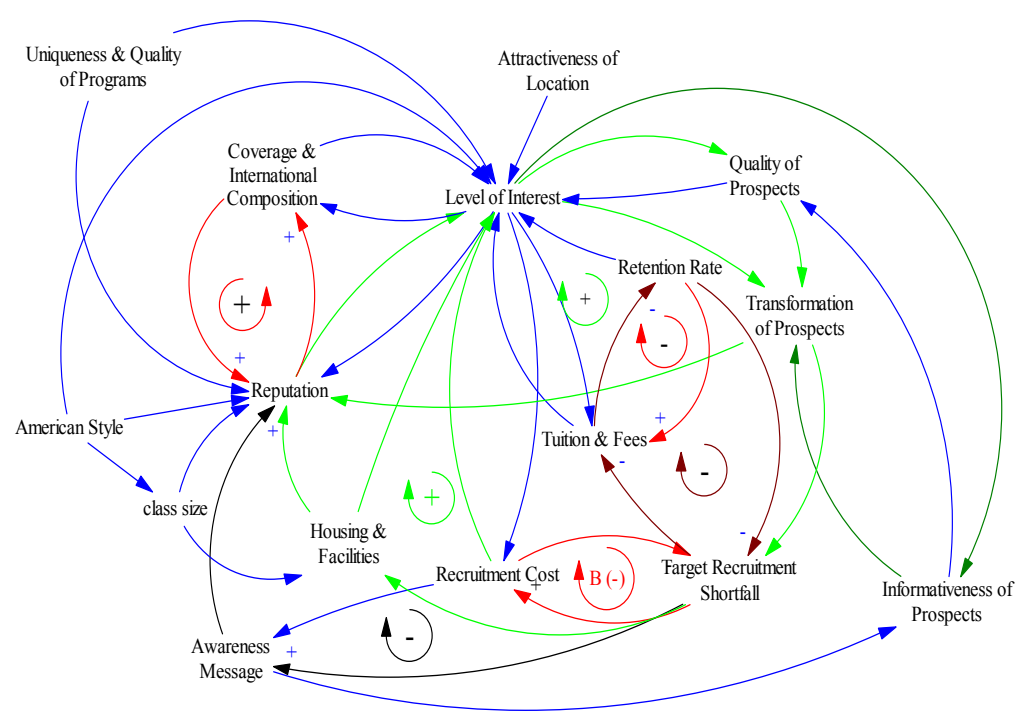

Figure 3. CLD for AUN CPE sub-committee of strategic planning

\section{Conclusion}

Given that this is a pilot study, the results are only preliminary and merely indicate how to improve policy and program decisions especially for AUN as a development university. The short time outcome and impact of the study has provided some insight into the college choice process of choosing a college using the CLD. Also it is important for admission professionals understand the factors that shape the college decision-making process and the stages students move through as they make decisions.

It is hoped that further research into these factors might yield findings to improve student choice, persistence and retention as well as increase achievement and graduation rates in our universities, especially in Nigeria.

This pilot study provides us with a unique opportunity to rethink the research design, data collection methods and tools as well as survey administration and analyses so that we might better design and help our prospective students and possibly parents make the right college choice. From the foregoing report, virtually all examined options seem to suggest common denominators in terms of advantages, problems, and solutions for the competitive positioning of AUN for a sustainable enrollment of outstanding students.

The following were some of the limitations of the study.

- The sample of this study consisted of participants from only one university (private) therefore, the results of this study were indicative of the characteristics of students in private universities. A more comprehensive sample is needed in order to have a more complete picture regarding university choice by students in Nigeria.

- Mixed methods data collection should be pursued. In depth interviews with a subsample to gather more information to explain why students and possibly parents choose the university they want to attend.

- Using Godratt, techniques for manually testing the validity of each link in a causal loop diagram using the eight possible validation criteria should be considered: clarity, connection edge, quantity existence, cause sufficiency, additional cause possibility, cause/effect reversal, predicted effect existence, and tautology.

\section{Recommendations}

The purpose of this preliminary but promising study, both with respect to the results and interpretations, was to explore why students in Nigeria choose the university they want to attend using CLD. As stated by Hossler and Palmer, the college decision-making process presumably has always been multifaceted and, in many instances, complicated. For example, as early as the 1920s education researches discussed how the college one attended had great bearing on one's future (Comfort; Halle 1928). Preliminary results show that a majority of students believe that AUN has a very good prospect of achieving its set goal as a development university if the standards and institutional characteristics can be sustained and improved upon. 
Therefore, we recommend the following as a way forward for AUN:

$\checkmark \quad$ There is an urgent need to involve other community members in student recruitment campaigns such as alumni, students, faculty and other staff outside of the office of Admissions.

$\checkmark$ Hiring of AUN alumni to run liaison offices and act as local recruitment coordinators in critical destinations such as Lagos, Port Harcourt, Ibadan, Kano, Warri, Kaduna, etc. has become a very real necessity.

$\checkmark \quad$ Mixing and matching other AUN events with recruitment activities such as Career Day, Leadership Lecture Series, Parents Forum, Open Houses, etc. are equally necessary.

$\checkmark \quad$ Building on existing partnerships with high schools and identifying new feeder schools and establishing close relations with them around Nigeria, West \& Central Africa.

$\checkmark \quad$ The newly inaugurated On-campus recruitment strategy seemed to be extremely successful and productive. In this regard, we need to sustain it and even accommodate more that one of such events per year, inviting different schools at each time.

$\checkmark \quad$ It is also highly recommended to send thank you letters and participation certificates to these schools for sending their students over to AUN.

$\checkmark \quad$ It would be wise to establish a tradition of hosting counselors of feeder schools during such AUN events as Founder's Day, Commencement, Matriculation, etc.

$\checkmark \quad$ Facility maintenance needs to take high priority by school management at all times.

$\checkmark$ Educating students, parents and counselors about the breakdown of AUN fees and why it is necessary to maintain them is important.

$\checkmark \quad$ There is need to add more sporting and recreational facilities for students and also increase the number of extra-curricular activities for them on campus.

$\checkmark$ Due to the natural craving for adventure and international experience, which is sometimes the reason for students preferring to travel abroad for studies, the study abroad program needs to be expanded to accommodate more students.

$\checkmark \quad$ In the long run AUN needs to introduce more academic programs in the fields of Engineering, Medicine, Law, Architecture, Natural Sciences, Education, Agriculture, etc.

$\checkmark \quad$ There is a need to continuously conduct a student survey among returning students and freshmen to establish whether AUN has a competitive advantage over other sister Universities are not.

$\checkmark \quad$ In achieving this objective, we need to know more about the kind of facilities and academic programs being offered in other competitive universities in the category of American University of Nigeria.

\section{Acknowledgments}

The authors would like to thank the President of AUN for her support towards the study. I also want to thank the members of the Competitive Positioning and Enrollment Committee (CPE) as part of the Strategic Planning Process at AUN and most especially Richard Akomodi who help with the analysis. Finally Professor Izhar UL-Haq, Director of research at the American University in the Emirates for his valuable contribution in the edition of the paper.

\section{References}

Behdad, K., Mohammad, R. G., Asso, H., \& Seyed, H. (2009). Using Causal Loop Diagram to Achieve a Better Understanding of E-Business Models. International Journal of Electronic Business Management, 7(3), $159-167$.

Bowen, H. (1977). Investment in Learning: The individual and social value of American Higher Education. San Francisco: Jossey Bass.

Bruce, C. (2004). Causal loop Diagrams in Information Systems Research into Strategic Alignment. University of Technology, Sydney, Australia.

Duke, R. (2005). Causal Loop Diagrams: Performance Improvement.

Hans, V. (2007). Intervening and Changing: Looking for Meaning in Interactions, Working Interactively with Causal Loop Diagrams: Intervention Choices and Paradoxes in Practical Applications (pp. 175-194). John Wiley \& Sons, Ltd.

Hanson, K., \& Litten, L. (1982). Mapping the road to academia: A review of research on women, men, and the 
college selection process. In P. Perun (Ed.), The Undergraduate Woman: Issues in Education. Lexington, MA: Lexington.

Hearn, J. (1984). The Relative Roles of academic Ascribed and Socioeconomic Characteristics in College Destinations. Sociology of Education, 57, 22-30. http://dx.doi.org/10.2307/2112465

Heller, D. E. (2001). The Effect of Tuition Prices and Financial Aid on Enrollment in Higher Education. Education Report.

Hossler, D., \& Gallagher, K. (1987). Studying college choice: A three phase model and the implication for policy makers. College and University, 2, 207-21.

Hossler, D., \& Palmer, M. (n.d.). Why understand Research on College Choice? Chapter 3. Indiana University.

Hossler, D., Schmit, J., \& Vesper, N. (1999). Going to College: How Social, Economic, and Educational Factors Influence the Decisions Students Make. Baltimore: Johns Hopkins University Press.

Jackson, G. (1978). Financial aid and student enrollment. Journal of Higher Education, 49, 548-574. http://dx.doi.org/10.2307/1981139

Jackson, G. (1982). Public efficiency and private choice in higher education. Educational Evaluation and policy Analysis, 4, 237-247.

James, R. E. (2011). Quality Management, Organization, and Strategy (6th ed.). South-Western CENGAGE Learning.

Jena, M. (2006). How Failure Breeds Success, Business Week.

Kenzie, J., Palmer, M., Hayek, J., Hossler, D., Jacob, S. A., \& Cummings, H. (n.d.). Fifty Years of College Choice: Social, Political and Institution Influence on College Decision Making process.

Lawal, B., \& Goyol, A. (2010). Report on comparative tuition and living expenses of selected Universities across the globe. Research in Higher Education.

Martin, S. (2003). Business Process Design: Correlates of Success and Failure. Quality management Journal, $10(2), 38-49$

McDonough, P. M. (1997): How Social Class and School Structure Opportunity. Chapter 5: Families, Friends and Finances.

McDonough, P. M. (2005). Counseling and College Counseling in America's High Schools.

Micheal, T. (2005). A project management Causal Loop Diagram. Accepted for the 2005 ARCOM Conference, London, UK, Sep 5-7.

Ozge, P., Dirk, V., \& Jac, V. (2007). Effects of Causal Loop Diagrams on Escalating Commitment. Nijmegen School of Management, Radboud University of Nijmegen.

Pascarella, E. T., \& Terenzini, P. T. (2005). How College Affect Students. San Francisco: Jossey-Bass.

Tierney, M. L. (1983). Student college Choice sets: Towards an empirical characterization. Research in higher Education, 18(3), 271-284. http://dx.doi.org/10.1007/BF00979600

Wellman, J., \& Ewell, P. (2007). Enhancing Student Success in Education: Summary Report of NPEC. Initiative and National Symposium on Post Secondary Student Success.

\section{Copyrights}

Copyright for this article is retained by the author(s), with first publication rights granted to the journal.

This is an open-access article distributed under the terms and conditions of the Creative Commons Attribution license (http://creativecommons.org/licenses/by/3.0/). 